\title{
Lymphocyte transformation in the mesenteric lymph nodes of patients with Crohn's disease
}

\author{
P. J. GUILlou, T. G. BRENNAN, AND G. R. GILES \\ From the University Department of Surgery, Leeds (St James's) University Hospital, Leeds
}

SUMMARY The response of lymphocytes from peripheral blood and mesenteric lymph nodes to stimulation with phytohaemagglutinin in vitro has been studied in eight patients suffering from active Crohn's disease. Patients with Crohn's disease exhibited reduced responses when compared with similar studies performed in control subjects. The impaired responses of circulating lymphocytes from these patients were marked on culture in autologous serum and were not improved by culture in homologous $\mathrm{AB}$ serum. Lymphocytes from lymph nodes directly draining diseased bowel exhibited lower responses than those from nodes at the root of the mesentery, which in turn were lower than those of circulating lymphocytes.

The intestinal mesentery of patients suffering from Crohn's disease is characterized by the presence of large fleshy lymph glands which are most prominent in the area of the diseased bowel. The aetiology of the lymphadenopathy is unknown but has been attributed to lymphatic obstruction (Thayer, 1970; Kalima, 1971), secondary inflammation (Van Patter, Barger, Dockerty, Feldman, Mayo, and Waugh, 1954), and to sarcoid granulomata (Reichert and Mather, 1936). It has also been suggested that the lymph node hyperplasia is the result of an immunological process within the diseased bowel and the associated lymph glands (Hadfield, 1939; Warren and Summers, 1948). However, previous immunological studies of patients with Crohn's disease have dealt mainly with the cell-mediated immune responses of lymphocytes circulating in the peripheral blood and have shown either depressed or normal reactivity to non-specific stimulation (Jones, Housley, Ashurst, and Hawkins, 1969; Walker and Greaves, 1969; Aas, Huizenga, Newcomer, and Shorter, 1972).

In this study we have compared the response of peripheral lymphocytes to phytohaemagglutin in (PHA) with the responses obtained in lymphocytes from mesenteric lymph nodes of a group of patients with Crohn's disease and another group of patients undergoing operation for non-inflammatory and non-malignant conditions of the gastrointestinal tract.

Received for publication 7 November 1972.

\section{Materials and Methods}

LYMPHOCYTE CULTURE TECHNIQUE

Peripheral blood lymphocytes were extracted from $20 \mathrm{ml}$ of defibrinated venous blood by a modification of the method of Coulson and Chalmers (1964). Lymph nodes removed at laparotomy were macerated and filtered through a $33 \mu$ diameter sterile sieve and suspended in TC199 (Burroughs Wellcome). Routine histology was performed on one half of each lymph node under investigation.

Lymphocyte cultures were performed in duplicate using $5 \mathrm{ml}$ aliquots of either $20 \%$ autologous serum or $20 \%$ homologous $A B$ serum obtained from a pool of five healthy donors. The sera were diluted with TC 199 containing antibiotics (penicillin 200 units $/ \mathrm{ml}$ and streptomycin $100 \mu \mathrm{g} / \mathrm{ml}$ ). The final cell concentration in these aliquots was $10^{6}$ cells per $\mathrm{ml}$. The culture media were placed in $20 \mathrm{ml}$ volume tissue culture flasks (Falcon Plastics) and to each was added $0.25 \mathrm{ml}$ of PHA (Burroughs Wellcome). Each culture was incubated for $71 \frac{1}{2} \mathrm{hr}$ after which $0.1 \mu \mathrm{Ci}$ of tritiated thymidine (Radiochemicals, Amersham) was added to the culture and incubation continued for a further 30 minutes. The cells were harvested and after washing twice in TC 199 smears were made on glass slides which were fixed with methanol after drying. Autoradiographs were prepared on the smears, these then being stained by conventional haematological methods (Giemsa). At least 3000 cells were counted for each culture and the number of transformed cells demon- 
strating uptake of radioactive thymidine was expressed as a percentage of the total number of cells counted (lymphocyte transformation rate $=$ LTR \%).

Cultures were prepared in the following groups.

\section{Subjects without Crohn's disease}

Peripheral blood lymphocytes cultured in $20 \%$ autologous serum, $20 \%$ homologous AB serum, $20 \%$ serum from age/sex-matched patients suffering from Crohn's disease; lymph node lymphocytes cultured in $20 \%$ autologous serum.

\section{Patients suffering from Crohn's disease}

Peripheral blood lymphocytes cultured in $20 \%$ autologous serum and $20 \%$ homologous AB serum.

Lymph node lymphocytes were cultured in $20 \%$ autologous serum.

\section{Clinical Groups}

\section{CONTROL SUBJECTS}

Peripheral blood lymphocytes were studied from 25 healthy subjects, a proportion of whom were age/sex-matched for the patients with Crohn's disease. Seven other subjects underwent laparotomy for the treatment of peptic ulceration, cholelithiasis, or hysterectomy, and lymph nodes were obtained from the root of the mesentery, paraileal, ileocaecal, and paracolonic situations. In all, 16 lymph nodes were studied.

\section{PATIENTS WITH CROHN'S DISEASE}

Six patients had ileocaecal involvement of long standing and two patients had recurrent ileitis just proximal to a previous resection. All patients underwent laparotomy and further resection. Lymph nodes were obtained from the area draining the diseased bowel and from the root of the mesentery or paraaortic regions. Seventeen lymph nodes were studied in all. None of these patients had undergone steroid or immunosuppressive therapy for at least three months before study.

\section{Results}

\section{PERIPHERAL BLOOD LYMPHOCYTES}

\section{Cultured in autologous serum}

The mean transformation rates (Fig. 1) of the peripheral blood lymphocytes from 25 healthy donors was $46.6 \pm 1.7 \%$ (range $36-64 \%$ ). The mean lymphocyte transformation rate (LTR) of eight normal subjects who were age/sex-matched to the patients with Crohn's disease was $48 \cdot 3 \pm$ $2 \cdot 3 \%$ (range $38-56 \%$ (Fig. 1)). This contrasted with the mean transformation rate of the eight

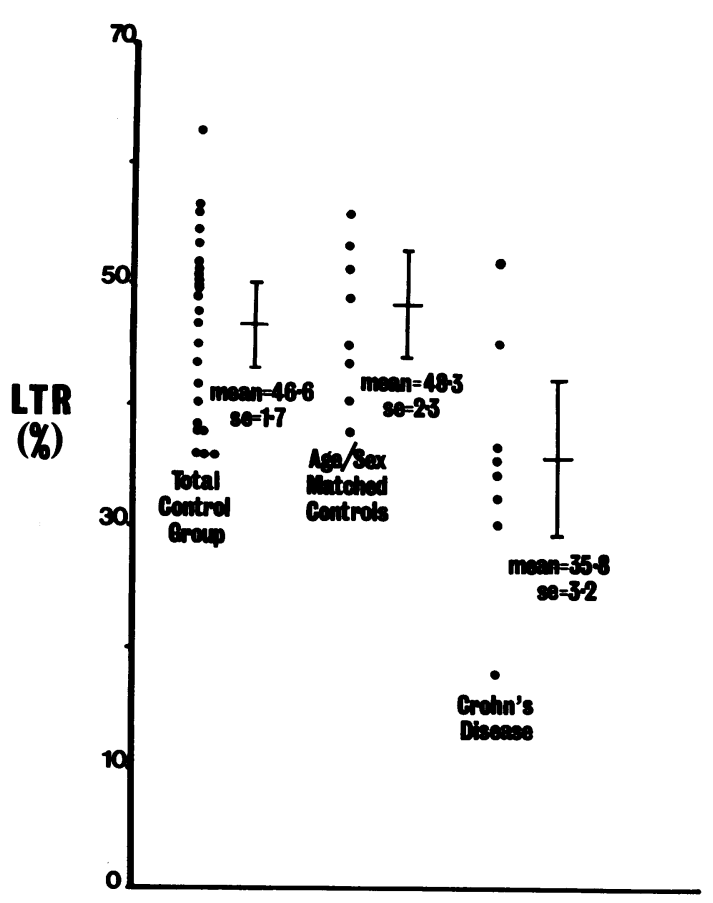

Fig. 1 The lymphocyte transformation rates (LTR) of the circulating lymphocytes from the control group (25 subjects), eight age/sex-matched control subjects, and the group of eight patients suffering from Crohn's disease.

patients with Crohn's disease of $35.8 \pm 3.2 \%$ (Fig. 1), the difference between the two groups being highly statistically significant $(t=7 \cdot 71$, $P=<0.002$ ).

Cultured in homologous $A B$ serum

The mean LTR of cells from the group of eight age/sex-matched healthy subjects was $48.8 \pm 3.0 \%$ whereas a value of $28.8 \pm 4.0 \%$ was obtained from the patients with Crohn's disease (Fig. 2). The difference between these two groups was found to be statistically significant $(\mathrm{P}=<0.002)$. All the cultures from the patients with Crohn's disease demonstrated a reduction in LTR when cultured in homologous $\mathrm{AB}$ serum when compared with culture in autologous serum (Fig. 2), the difference being statistically significant $(t=2 \cdot 71, P=<0.05)$.

Cultured in serum from patients with Crohn's disease Peripheral blood lymphocytes were obtained from seven healthy individuals found to have a mean LTR in autologous serum of $43.8 \pm 2.9 \%$. These cells were also cultured with the serum from the patients with Crohn's disease, each being matched 
for age and sex, and a mean LTR of $43.1 \pm 3.8 \%$ was obtained. Two subjects showed moderate elevations and one subject a small depression of the lymphocyte transformation rate.

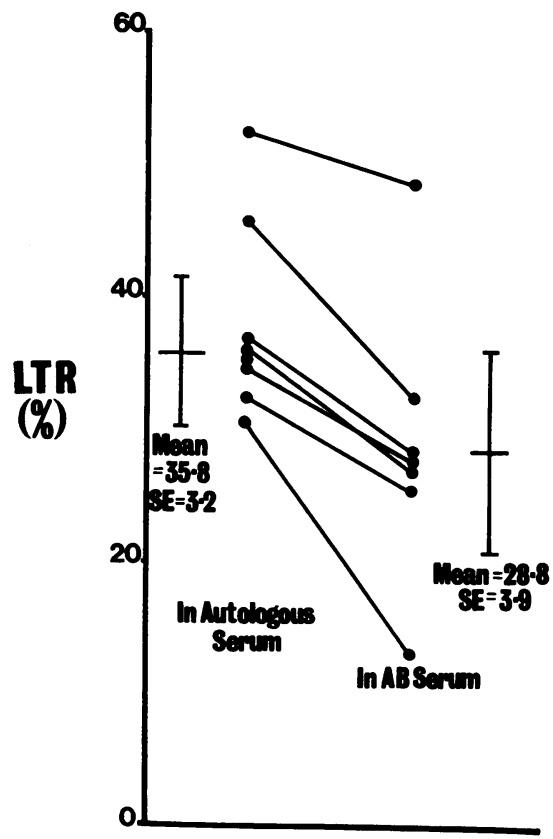

Fig. 2 Lymphocyte transformation rates (LTR) of circulating lymphocytes from patients with Crohn's disease cultured in $20 \%$ autologous serum and in $20 \%$ homologous group $A B$ serum.

\section{LYMPH NODE LYMPHOCYTES CULTURED IN} AUTOLOGOUS SERUM

The mean LTR of the 16 lymph nodes obtained at laparotomy from patients without Crohn's disease was $42.6 \pm 2.2 \%$. This compared with a mean of $22 \cdot 8 \pm 4.0 \%$ from the 17 lymph nodes obtained from the patients suffering from Crohn's disease. This difference is found to be highly significant statistically $(\mathrm{t}=5.52, \mathrm{P}=<0.002)$.

In Figure 3 it can be seen that in patients without Crohn's disease the mean LTR of lymph node lymphocytes in a juxtaintestinal situation (six nodes) was $44.8 \pm 3.3 \%$ and the LTR of those at the root of the mesentery was $43.1 \pm 4.0 \%$. Thus in this group of patients there was no difference between lymphocytes obtained from the peripheral blood and either of the two lymph node sites.

Figure 3 also demonstrates the LTR of the cells obtained from the 10 nodes closely associated with diseased bowel. These have an LTR of $19.9 \pm 3.3 \%$ which contrasts with a value of $28.2 \pm 4.9 \%$ for the cells obtained at the root of the mesentery. In all of these patients studied there appeared to be a gradient in the degree of non-reactivity to PHA along the route of lymphatic drainage of the diseased bowel. These differences were significant between the peripheral blood and proximal lymph nodes $(t=3.57, P=<0.05)$ and between the proximal and juxtaintestinal nodes $(t=2 \cdot 45$, $P<0.05)$.

\section{HISTOPATHOLOGICAL STUDIES}

The diagnosis of regional enteritis was confirmed

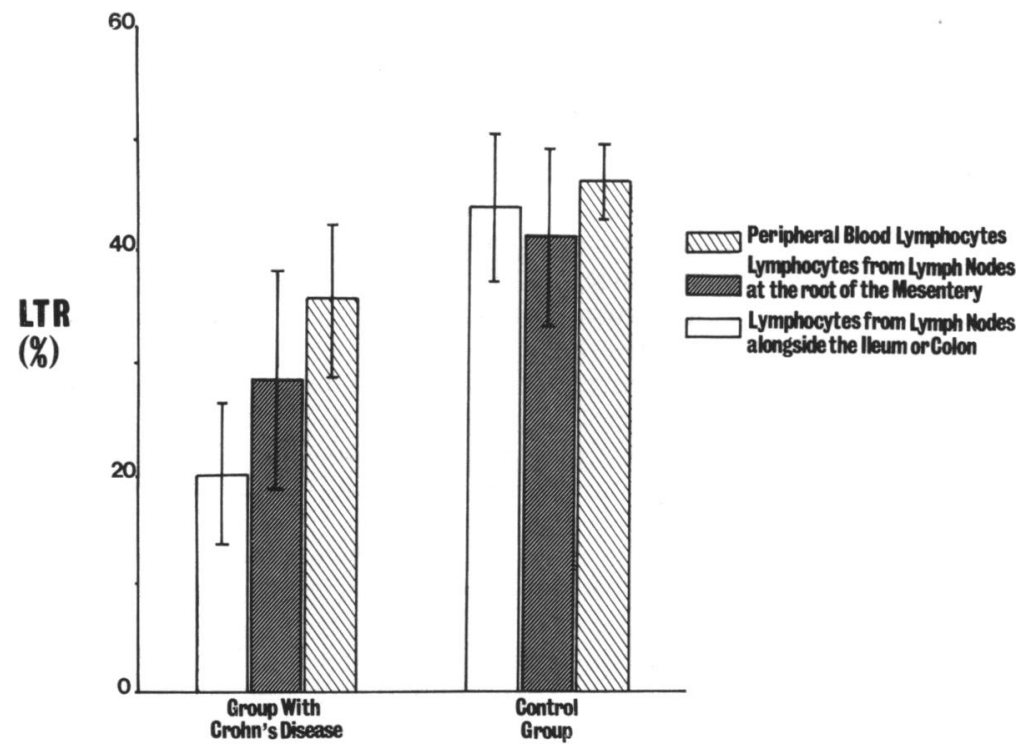

Fig. 3 The mean lymphocyte transformation rates $(L T R)$ of lymphocytes obtained from peripheral blood, lymph nodes at the root of the mesentery, and nodes adjacent to the ileum or colon. 
by histology in all cases. At least three sections of each lymph node were examined and all showed changes of lymphocyte aggregation, prominent germinal centres, and increased plasma cells. Nodes from two patients also showed prominent granulomata. The histological appearances of the nodes from the patients without Crohn's disease were normal.

The LTR of the two patients with lymph node granulomata was 5 and $17 \%$ in the juxtaintestinal nodes, 24.9 and $26.6 \%$ in the more proximal nodes, and 34.6 and $32.6 \%$ in the peripheral blood. This compared with a mean LTR of $21.6 \%$ (juxtaintestinal), $28.9 \%$ (proximal), and $36.5 \%$ in the peripheral blood in the remainder of the group of patients with Crohn's disease.

\section{Discussion}

Investigation of the immunological reactivity of patients with Crohn's disease has been of interest for many years. Initial studies appeared to show impaired responses to tuberculin injections (Blackburn, Hadfield, and Hunt, 1939; Phear, 1958; Williams, 1965). These findings were refuted by the more controlled observations of Fletcher and Hinton (1967), and Binder, Spiro, and Thayer (1966) were able to show normal skin reactions to oidiomycin, tricophytin, and mumps antigens. However, in a more dynamic test of delayed hypersensitivity reactions, Jones et al (1969) found it impossible to sensitize 15 of 26 patients with Crohn's disease to dinitrochlorbenzene. This apparent depression of lymphocyte immunological competence was confirmed by Walker and Greaves (1969), who demonstrated that the peripheral lymphocytes of patients with Crohn's disease had a diminished response in vitro to phytohaemagglutinin when compared with normal age/sex-matched individuals.

These findings are confirmed by the present studies with transformation rates of peripheral lymphocytes in autologous serum of $35.8 \%$ in the patients with Crohn's disease compared to $48.3 \%$ in the normal subjects. The depressed responses of the peripheral lymphocytes in Crohn's disease could be explained by the presence of a serum inhibitory factor, in the same manner that has been postulated for patients with malignant disease (Whittaker, Rees, and Clark, 1971). However, lymphocyte transformation was not improved by culture in homologous $\mathrm{AB}$ serum, and in fact resulted in decreases in transformation rates in all cultures. The reason for this decrease is not clear but suggests that the autologous serum of these patients has some sustaining quality rather than any inhibitory factor. Similarly, the culture of normal peripheral lymphocytes in serum from patients with Crohn's disease did not diminish the response to phytohaemagglutinin. These findings suggest that the cause of the depressed responses in peripheral lymphocytes lies within the lymphocyte itself.

The mesenteric lymph nodes of patients with Crohn's disease are usually enlarged and on histology show increased aggregations of lymphocytes, increased numbers of plasma cells, reticuloendothelial proliferation, and, most characteristically, noncaseating granulomata. These features would, at first sight, suggest that the nodes are involved in an intense immunological response. It is remarkable, therefore, that the lymphocytes isolated from these nodes show depressed responses to PHA to a degree that is more severe than that seen in the peripheral blood. Cells from nodes close to the diseased bowel have extremely low transformation rates $(19.9 \%)$ when compared with cells from nodes taken from the root of the mesentery $(28.2 \%)$. In the patients undergoing laparotomy for conditions other than Crohn's disease, the transformation rates for cells from the two groups of lymph nodes and the peripheral blood were identical.

Attempts to correlate lymphocyte transformation rates to the histopathological appearances in the lymph node were not entirely satisfactory. All nodes showed changes which have been labelled reactive hyperplasia and nodes from two patients had granulomata in them. The lymphocytes in these nodes had particularly low transformation rates. However, low transformation rates were also seen in cells from other patients in whom granulomata were absent. The gradient of responses to PHA by the lymphocytes from juxtaintestinal nodes to the peripheral blood suggests that the lymphocytes are depressed by some action within the diseased intestine. These cells might then migrate through the lymph nodes eventually to circulate within the blood stream and account for the lower transformation rates to phytohaemagglutinin.

Though the non-specific immunological responses of lymphocytes in patients with Crohn's disease are apparently lower than in control subjects, the results of this study do not exclude an immunological basis for this disease process. Cells which have already undergone stimulation in vivo are less likely to respond to PHA stimulation in vitro. Thus under these circumstances the result of immunological activity in the lymph nodes may manifest as low transformation rates in cell culture, with an increased proportion of large to small lymphocytes on histological examination. Since the lymphocytes which respond to PHA are all thymic derived, an alternative explanation of the lower transformation rates in patients with Crohn's disease might result 
from the nodes and peripheral blood containing a higher proportion of bone marrow-derived lymphocytes which are not responsive to phytohaemagglutinin. It may now be possible to settle this point by techniques which demonstrate immunoglobulins on the surface of bone marrow-derived lymphocytes (Papamichail, Brown, and Holbrow, 1971). Some support for a dual cell population is suggested by the work of Brown, Taub, Present, and Janowitz, (1970), who demonstrated that the peripheral lymphocytes from patients with Crohn's disease showed normal responses to Pokeweed mitogen whilst exhibiting reduced response to ConcanavalinA and PHA when compared with cells from normal subjects.

Thus, while it is improbable that the lymphadenopathy of Crohn's disease is attributable to an immunological reaction involving thymus-derived cells, it is still possible that the enlarged nodes result from an immunological process involving bonemarrow-derived lymphocytes.

\section{References}

Aas, J., Huizenga, K. A., Newcomer, A. D., and Shorter, R. G. (1972). Inflammatory bowel disease: lymphocytic responses to non-specific stimulation in vitro. Scand. J. Gastroent., 7, 299-303.

Binder, H. J., Spiro, H. M., and Thayer, W. R., Jr. (1966). Delayed hypersensitivity in regional enteritis and ulcerative colitis. Amer. J. dig. Dis., 11, 572-574.
Blackburn, G., Hadfield, G., and Hunt, A. (1939). Regional ileitis. St Bart. Hosp. Rep., 72, 181-224.

Brown, S. M., Taub, R. N., Present, D. H., and Janowitz, H. D. (1970). Short-term lymphocyte cultures in regional enteritis. (Letter). Lancet, 1, 1112.

Coulson, A. S., and Chalmers, D. G. (1964). Separation of viable lymphocytes from human blood. Lancet, 1, 468-469.

Fletcher, J., and Hinton, J. M. (1967). Tuberculin sensitivity in Crohn's disease. Lancet, 2, 753-754.

Hadfield, G. (1939). The primary histological lesion of regional ileitis. Lancet, 2, 773-775.

Jones, J. V., Housley, J., Ashurst, P. M., and Hawkins, C. F. (1969). Development of delayed hypersensitivity to dinitrochlorobenzene in patients with Crohn's disease. Gut, 10, 52-56.

Kalima, T. V. (1971). The structure and function of intestinal lymphatics and the influence of impaired lymph flow on the ileum of rats. Scand. J. Gastroent., 6, Suppl. 10.

Papamichail, M., Brown, J. C., and Holbrow, E. J. (1971). Immunoglobulins on the surface of human lymphocytes. Lancet, 2, 850-852.

Phear, D. N. (1958). The relation between regional ileitis and sarcoidosis. Lancet, 2, 1250-1251

Reichert, F. L., and Mathes, M. E. (1936). Experimental lymphedema of the intestinal tract and its relation to regional cicatrising enteritis. Ann. Surg., 104, 601-614.

Thayer, W. R., Jr. (1970). Crohn's disease (regional enteritis). A look at the past four years. Scand. J. Gastroent., 5, Suppl. 6, 165-185.

Van Patter, W. N., Bargen, J. A., Dockerty, M. B., Feldman, W. H., Mayo, C. W., and Waugh, J. M. (1954). Regional enteritis. Gastroenterology, 26, 347-450.

Walker, J. G., and Greaves, M. F. (1969). Delayed hypersensitivity and lymphocyte transformation in Crohn's disease and proctocolitis. (Abstr.) Gut, 10, 414.

Warren, S., and Sommers, S. C. (1948). Cicatrising enteritis (regional ileitis) as a pathological entity: an analysis of 120 cases. Amer. J. Path., 24, 475-501.

Whittaker, M., Rees, K., and Clark, C. G. (1971). Reduced lymphocyte transformation in breast cancer. Lancet, $1,892-893$.

Williams, W. J. (1963). The laboratory diagnosis of Crohn's syndrome. Proc. roy. Soc. Med., 56, 490. 